\title{
The COVID 19 novel coronavirus pandemic 2020: seaweeds to the rescue? Why does substantial, supporting research about the antiviral properties of seaweed polysaccharides seem to go unrecognized by the pharmaceutical community in these desperate times?
}

\author{
Leonel Pereira ${ }^{1}$ (D) - Alan T. Critchley ${ }^{2}$ \\ Received: 8 April 2020 / Revised and accepted: 27 April 2020 / Published online: 1 June 2020 \\ (C) Springer Nature B.V. 2020
}

\begin{abstract}
Presently, there is lack of a vaccine that would lead to immunization against the virus COVID-19, but here are some of the characteristics that various seaweeds have and which may provide a glimpse into potential solutions of this global health problem in the near future and possibly forearm us for any future such pandemics. Many species of marine algae contain significant quantities of complex structural sulphated polysaccharides that have been shown to inhibit the replication of enveloped viruses. Other compounds, both of red algae (e.g., the lectin griffithsin and the phycocolloid carrageenan), and other sulphated polysaccharides extracted from green algae (i.e., ulvans) and brown algae (i.e., fucoidans) could be potential antiviral therapeutic agents against SARS-CoV-2.
\end{abstract}

Keywords COVID-19 · Novel coronavirus · Pandemic 2020 • Seaweed compounds · Sulphated polysaccharides · Antiviral properties

At this current point in human history (April 2020), global society faces a Herculean challenge in combating the pandemic COVID-19. Presently, there is lack of a vaccine that would lead to immunization against this virus, but here are some of the characteristics that various seaweeds have and which may provide a glimpse into potential solutions of this global health problem in the near future and possibly forearm us for any future such pandemics.

Historically, Irish moss or carrageen (this is an unspecified mixture of naturally co-occurring red seaweeds, Chondrus crispus and Mastocarpus stellatus) has a large number of medical applications, some of which date from the 1830s.

Leonel Pereira

leonel.pereira@uc.pt

Alan T. Critchley

alan.critchley2016@gmail.com

1 University of Coimbra, Marine and Environmental Sciences Centre (MARE), Department of Life Sciences, 3000-456 Coimbra, Portugal

2 Verschuren Centre for Sustainability in Energy and Environment, Cape Breton University, Sydney, Nova Scotia, Canada
Indeed, it is still used in Ireland to make traditional medicinal teas and cough medicines to combat colds, bronchitis, and chronic coughs. It is said to be particularly useful for dislodging mucus and has antiviral properties (Pereira 2018a).

The viruses that infect humans reflect only a small part of the spectrum of the multitude of different types whose host ranges extend from vertebrates to protozoa and from plants and fungi to bacteria (Gelderblom 1991). Therefore, Picornavirales, Ortervirales, and Nidovirales can cause a large number of human diseases (Soares 2015; Styczyński 2019).

The incidences of emerging and/or re-emerging viral infections have significantly affected human health since antiquity. Emerging pathogens are defined as new etiologic agents that have recently been introduced into a population. The "Spanish flu," responsible for tens of millions of casualties in the early twentieth century, was a natural calamity, one of the most devastating in human history. The flu pandemic returned in 1957 as an "Asian flu" and then again in 1968 as a "Hong Kong flu" which killed about three million people. The most recent flu re-emergence on this scale was in 2009 with "swine flu" that took 18,500 lives. In its pandemic course during 2002-2003, a new coronavirus, or severe 
acute respiratory syndrome (SARS-CoV), infected more than 8000 people, causing 774 deaths in 27 countries (Parvez and Parveen 2017).

Acute respiratory infections (ARIs) are the major cause of childhood morbidity and mortality worldwide. Viruses account for the majority of ARIs in young children, and most infections are attributed to respiratory syncytial virus (RSV), parainfluenza virus (PIVs), influenza virus (FluV), rhinovirus (RV), and adenovirus (AdV) (Monto 2002; Mackay et al. 2003; Weigl et al. 2007; Canducci et al. 2008). Over the past few years, newly described viruses were associated to respiratory infection, such as human metapneumovirus (HMPV), the emerging human coronaviruses $(\mathrm{HCoV})$, human bocavirus (HBoV), and the new human papilloma viruses KIPyV and WUPyV (Kahn 2007; Sloots et al. 2008).

The current outbreak of an acute respiratory disease associated with a coronavirus, called coronavirus disease 19 (COVID-19), is the third documented leak of an animal coronavirus for humans in just two decades, which resulted in a major epidemic (the 19 epithet refers only to the year it was reported, 2019). The Coronaviridae Study Group (CSG) of the International Virus Taxonomy Committee, responsible for the development of the virus classification and nomenclature of the taxa of the Coronaviridae family, evaluated the placement of the human pathogen, provisionally named 2019-nCoV, within the Coronaviridae. Based on phylogeny, taxonomy, and established practice, the CSG recognizes this virus as a clone associated with the coronavirus prototype of the severe acute human respiratory syndrome and bat (SARS-CoVs) of the coronavirus species related to severe acute respiratory syndrome, referred to as SARS-CoV-2 (Gorbalenya et al. 2020; Wang et al. 2020).

Interestingly, the low initial levels of COVID-19 infection in Japan, specifically in Hokkaido, were possibly related to the traditional and widespread consumption of seaweed and the regular supply of iodine in their diet. However, subsequently, the number of infected with COVID-19 increased dramatically, as regulations on detachment and testing for contagion with this disease were greatly reduced (Booker 2020). These reports suggest that seaweed helped Hokkaido populations to reduce contagion in an initial period, but their consumption was not a $100 \%$ effective weapon, requiring additional measures of isolation and/or social distancing.

Acute viral upper respiratory tract infection, also known as the common cold, is the most frequently observed infectious disease in human beings. Children get four to eight upper respiratory infections per year, and adults suffer from two to four episodes per year (Goldmann 2001). In most of cases, the common cold is caused by respiratory viruses such as rhinovirus, coronavirus, parainfluenza, influenza, respiratory syncytial virus, adenovirus, enterovirus, and metapneumovirus (Monto and Sullivan 1993; Makela et al. 1998; Monto et al. 2001; Monto 2002). According to the work of Koenighofer et al. (2014), the administration of a carrageenan nasal spray, in children as well as in adults, suffering from virus-confirmed common cold reduced the duration of disease, increased viral clearance, and reduced relapses of symptoms. Carrageenan nasal spray appeared as an effective treatment of the common cold in children (sometimes recognized as "super-shedders") and adults (Eccles et al. 2010, 2015; Koenighofer et al. 2014).

A nasal spray containing only iota-carrageenan, or together with "zanamivir," was shown to provide an easy-to-apply treatment of upper respiratory tract infections in patients under suspicion of infection by influenza A (H1N1) (Leibbrandt et al. 2010; Morokutti-Kurz et al. 2015). Patients were found to benefit from the fast and efficient treatment of an uncomplicated influenza of the upper respiratory tract. Due to faster clearance of the influenza virus from the upper respiratory tract and the independent anti-viral mechanism of carrageenan and "zanamivir," the likelihood of developing escaped mutations against "zanamivir" would be reduced. Both individual compounds can reduce the severity and/or duration of the influenza illness, and a combination is expected to work similarly, if not synergistically (Morokutti-Kurz et al. 2015).

Additionally, due to the broad antiviral effectiveness of carrageenan, patients would receive, in parallel, a concomitant treatment for additional viral infections. Therefore, patients would benefit from a decreased probability for the development of further complications. In consideration of the complications known to accompany an influenza virus illness, this combinational therapy meets an urgent medical need (Leibbrandt et al. 2010; Morokutti-Kurz et al. 2015). The pharmaceutical company Boehringer Ingelheim sells a nasal spray called Bisolviral ${ }^{\circledR}$, which uses the bioactivity of iota-carrageenan (Eccles et al. 2010, 2015; Koenighofer et al. 2014).

In recent years, the constant outbreak of some emerging or re-emerging viral diseases has caused serious harm to human health. During the last decades, the number of antiviral products approved for clinical use has been increased from 5 to more than 30 drugs. The potential antiviral activity of marine algal polysaccharides was first shown by Gerber et al. (1958), describing that the polysaccharides extracted from the red alga Gelidium robustum (formerly Gelidium cartilagineum) (Rhodophyta) protecting embryonic eggs against influenza B or mumps virus. Many species of marine algae contain significant quantities of complex structural sulphated polysaccharides that have been shown to inhibit the replication of enveloped viruses including members of the Nidovirales. Other compounds, both of red algae (e.g., the lectin griffithsin), and other sulphated polysaccharides extracted from green algae (i.e. ulvans) and brown algae (i.e. fucoidans) could be potential antiviral therapeutic agents against SARS-CoV-2 (O'Keefe et al. 2010, Barton et al. 2014, Shi et al. 2017, Pereira 2018b, Barre et al. 2019, Lee 2019, Rosa et al. 2019). 
Funding information This work was financed by national funds through the FCT - Foundation for Science and Technology, I.P., within the scope of the projects UIDB/04292/2020 - (MARE) Marine and Environmental Sciences Centre.

\section{References}

Barre A, Simplicien M, Benoist H, Van Damme EJM, Rouge P (2019) Mannose-specific lectins from marine algae: diverse structural scaffolds associated to common virucidal and anti-cancer properties. Mar Drugs 17:440

Barton C, Kouokam JC, Lasnik AB, Foreman O, Cambon A, Brock G, Montefiori DC, Vojdani F, McCormick AA, O'Keefe BR, Palmer KE (2014) Activity of and effect of subcutaneous treatment with the broad-spectrum antiviral lectin griffithsin in two laboratory rodent models. Antimicrob Agents Chemother 58:120-127

Booker B (2020) Japan declares nationwide state of emergency as coronavirus spreads. NPR (National Public Radio). Available at: https:// www.npr.org/sections/coronavirus-live-updates/2020/04/16/ $835925031 /$ japans-declares-nationwide-state-of-emergency-ascoronavirus-spreads (accessed on Apr 22, 2020)

Canducci F, Debiaggi M, Sampaolo M, Marinozzi MC, Berre S, Terulla C, Gargantini G, Cambieri P, Romero E, Clementi M (2008) Twoyear prospective study of single infections and co-infections by respiratory syncytial virus and viruses identified recently in infants with acute respiratory disease. J Med Virol 80:716-723

Eccles R, Meier C, Jawad M, Weinmullner R, Grassauer A, PrieschlGrassauer E (2010) Efficacy and safety of an antiviral iotacarrageenan nasal spray: a randomized, double-blind, placebo controlled exploratory study in volunteers with early symptoms of the common cold. Respir Res 11:108

Eccles R, Winther B, Johnston SL, Robinson P, Trampisch M, Koelsch S (2015) Efficacy and safety of iota-carrageenan nasal spray versus placebo in early treatment of the common cold in adults: the ICICC trial. Respir Res 16:121

Gelderblom HR (1991) Assembly and morphology of HIV: potential effect of structure on viral function. AIDS 5(6):617-637

Gerber P, Dutcher JD, Adams EV, Sherman JH (1958) Protective effect of seaweed extracts for chicken embryos infected with influenza B or mumps. Proc Soc Exp Biol Med 99:590-593

Goldmann DA (2001) Epidemiology and prevention of pediatric viral respiratory infections in health-care institutions. Emerg Infect Dis 7:249-253

Gorbalenya AE, Baker SC, Baric RS, de Groo RJ, Drosten C, Gulyaeva AA, Haagmans BL, Lauber C, Leontovich AM, Neuman BW et al (2020) The species severe acute respiratory syndrome-related coronavirus: classifying 2019-nCoV and naming it SARS-CoV-2. Nat Microbiol 5:536-544

Kahn JS (2007) Newly discovered respiratory viruses: significance and implications. Curr Opin Pharmacol 7:478-483

Koenighofer M, Lion T, Bodenteich A, Prieschl-Grassauer E, Grassauer A, Unger H, Mueller CA, Fazekas T (2014) Carrageenan nasal spray in virus confirmed common cold: individual patient data analysis of two randomized controlled trials. Multidiscip Respir Med 9:57

Lee C (2019) Griffithsin, a highly potent broad-spectrum antiviral lectin from red algae: from discovery to clinical application. Mar Drugs 17:567

Leibbrandt A, Meier C, König-Schuster M, Weinmüllner R, Kalthoff D, Pflugfelder B, et al. (2010) Iota-carrageenan is a potent inhibitor of Influenza A virus infection. PLoS One 5:e14320
Mackay IM, Jacob KC, Woolhouse D, Walker K, Syrmis MW, Whiley DM, Nissen M, Sloots TP (2003) Molecular assays for detection of human metapneumovirus. J Clin Microbiol 2003:100-105

Makela MJ, Puhakka T, Ruuskanen O, Leinonen M, Saikku P, Kimpimaki M, Blomqvist S, Hyypia T, Arstila P (1998) Viruses and bacteria in the etiology of the common cold. J Clin Microbiol 36:539-542 PMC104573

Monto AS (2002) Epidemiology of viral respiratory infections. Am J Med 112:4S-12S

Monto AS, Sullivan KM (1993) Acute respiratory illness in the community. Frequency of illness and the agents involved. Epidemiol Infect 110:145-160

Monto AS, Fendrick AM, Sarnes MW (2001) Respiratory illness caused by picornavirus infection: a review of clinical outcomes. Clin Ther 23:1615-1627

Morokutti-Kurz M, König-Schuster M, Koller C, Graf C, Graf P, Kirchoff N, Reutterer B, Seifert J-M, Unger H, Grausser A, Prieschl-Grassauer NS (2015) The intranasal application of Zanamivir and carrageenan is synergistically active against influenza A virus in the murine model. PLoS One 10:e0128794

O'Keefe BR, Giomarelli B, Barnard DL, Shenoy SR, Chan PK, McMahon JB, Palmer KE, Barnett BW, Meyerholz DK, Wohlford-Lenane CL et al (2010) Broad-spectrum in vitro activity and in vivo efficacy of the antiviral protein griffithsin against emerging viruses of the family Coronaviridae. J Virol 84:2511-2521

Parvez MK, Parveen S (2017) Evolution and emergence of pathogenic viruses: past, present, and future. Intervirology $60: 1-7$

Pereira L (2018a) Biological and therapeutic properties of the seaweed polysaccharides. Int Biol Rev 2:1-50

Pereira L (2018b) Antiviral activity of seaweeds and their extracts. In: Pereira L (ed) Therapeutic and Nutritional Uses of Algae. Science Publishers, Boca Raton, pp 175-211

Rosa GP, Tavares WR, Sousa PMC, Pages AK, Seca AML, Pinto D (2019) Seaweed secondary metabolites with beneficial health effects: an overview of successes in in vivo studies and clinical trials. Mar Drugs 18:8

Shi Q, Wang A, Lu Z, Qin C, Hu J, Yin J (2017) Overview on the antiviral activities and mechanisms of marine polysaccharides from seaweeds. Carbohydr Res 453-454:1-9

Sloots TP, Whiley DM, Lambert SB, Nissen MD (2008) Emerging respiratory agents: new viruses for old diseases. J Clin Virol 42:233243

Soares F (2015) Antifungal, antibacterial and antiviral activity of Chondracathus teedei var. lusitanicus (Gigartinaceae, Rhodophyta). MSc thesis, University of Coimbra, Coimbra, Portugal, $154 \mathrm{pp}$.

Styczyński J (2019) ABC of viral infections in hematology: focus on herpesviruses. Acta Haematol Pol 50:159-166

Wang S, Zhang Y, Liu S, Peng H, Mackey V, Sun L (2020) Coronaviruses and the associated potential therapeutics for the viral infections. J Infect Dis Ther 8:417

Weigl JAI, Puppe W, Meyer CU, Berner R, Foster J, Schmitt HJ, Zepp F (2007) Ten years' experience with year-round active surveillance of up to 19 respiratory pathogens in children. Eur J Pediatr 166:957966

Publisher's note Springer Nature remains neutral with regard to jurisdictional claims in published maps and institutional affiliations. 